\title{
Composição do leite humano: o alimento ideal
}

\author{
Human milk composition: the ideal nutrition for \\ infants
}

\author{
Valdenise Martins Laurindo Tuma Calil(1), Mário Cícero Falcão(1)
}

\begin{abstract}
Calil VMLT, Falcão MC. Composição do leite humano: o alimento ideal. Rev Med (São Paulo) 2003 jan.dez.;82(1-4):1-10.

RESUMO: Todas as mães devem ser encorajadas a oferecer seu próprio leite para seus filhos. Apesar do advento das fórmulas infantis, nenhuma dessas se equipara ao leite humano. O leite humano possui inúmeras vantagens: aspectos higiênicos, imunológicos, psico-sociais e cognitivo, bem como aquelas relativas à prevenção de doenças futuras; devem ser consideradas ainda as vantagens econômicas provenientes do menor custo e do efeito anticoncepcional, bem como os benefícios do aleitamento sobre o organismo materno. O leite humano possui uma composição nutricional balanceada em termos de proteínas, carboidratos e gorduras, promovendo crescimento e desenvolvimento adequados. Por isto, a alimentação de recém-nascidos e lactentes com o leite de suas próprias mães é recomendado durante dois primeiros anos de vida.
\end{abstract}

DESCRITORES: Leite humano/química. Leite humano/metabolismo. Nutrição infantil. Aleitamento materno.

\section{INTRODUÇÃO}

O leite humano é considerado o alimento ideal para o recém-nascido $(\mathrm{RN})^{1,2,3}$. Sabe-se que o leite produzido por mães saudáveis é suficiente para suprir todas as necessidades nutricionais do $\mathrm{RN}$ de termo durante os primeiros seis meses de vida, permitindo que ele permaneça em aleitamento materno exclusivo durante esse importante período de sua vida ${ }^{2}$.

O leite humano possui uma composição nutricional balanceada, que inclui todos os nutrientes essenciais, além de um grande número dos condicionalmente essenciais e de aproximadamente 45 tipos diferentes de fatores bioativos; muitos desses fatores parecem contribuir para o crescimento e desenvolvimento do $\mathrm{RN}$, bem como para a maturação de seu trato gastrintestinal ${ }^{4,5}$. Dentre eles destacam-se fatores antimicrobianos, agentes antiinflamatórios, enzimas digestivas, vários tipos de hormônios e fatores de crescimento ${ }^{5,6}$.

Os inúmeros benefícios do aleitamento materno para o organismo infantil incluem aspectos higiênicos, imunológicos, psico-sociais e cognitivo, bem como aqueles

\footnotetext{
(1) Doutor(a) em Pediatria pela FMUSP. Professor(a) Colaborador(a) do Departamento de Pediatria da FMUSP. Médico(a) Assistente do Berçário Anexo à Maternidade do Hospital das Clínicas da FMUSP. Endereço para correspondência: Al. Itu, 1299/72. CEP: 01421-001 - São Paulo, SP. e-mail: rtc@ @ibpinesp.com.br
} 
relativos à prevenção de doenças futuras ${ }^{7,8,9,10}$; devem ser consideradas ainda as vantagens econômicas provenientes do menor custo e do efeito anticoncepcional, bem como os benefícios do aleitamento sobre o organismo materno ${ }^{2}$.

\section{Estágios da lactação}

As modificações detectadas na composição do leite humano de acordo com o tempo de lactação parecem vir de encontro às necessidades variáveis do lactante, cuja velocidade de crescimento sofre acentuada redução com o passar dos meses ${ }^{5}$.

Nos primeiros dias após o parto, é produzido o colostro. Quando comparado ao leite maduro, ele é mais viscoso, possuindo maiores concentrações de proteínas, minerais e vitaminas lipossolúveis, particularmente A, E e carotenóides, bem como menores quantidades de lactose, gorduras e vitaminas do complexo $\mathrm{B}^{1,11}$. Seu conteúdo energético oscila ao redor de $58 \mathrm{kcal} / 100 \mathrm{ml}$, em contraste com as $71 \mathrm{kcal} / 100 \mathrm{ml}$ existentes no leite maduro. Caracteriza-se ainda por conter resíduos de materiais celulares presentes na glândula mamária e dutos por ocasião do parto ${ }^{1,11}$.

O colostro é muito rico em fatores de defesa, como imunoglobulinas e outros agentes antimicrobianos, substâncias imunomoduladoras, agentes antiinflamatórios, dentre os quais se destacam os fatores de crescimento ou tróficos, e ainda os leucócitos ${ }^{12}$.

As imunoglobulinas representam a maior parte da fração protéica do colostro, constituindo, nessa fase da lactação, elementos de capital importância na proteção do RN contra microrganismos presentes no canal de parto ${ }^{13,14}$. Os níveis de anticorpos sofrem rápido e acentuado declínio nos primeiros dias de vida, sendo seus valores com 72 horas apenas $20 \%$ daqueles das primeiras 24 horas $^{13,14}$.

A duração do período de colostro não é bem definida, existindo grandes variações individuais. Macy ${ }^{11}$ considera como colostro, numa tentativa de uniformização, a produção láctea do primeiro ao quinto dias pós-parto. Segundo o Ministério da Saúde ${ }^{15}$, entretanto, o período de colostro se estende até o sétimo dia pós-parto.

As modificações na composição láctea após o quinto dia ocorrem de forma gradual e progressiva, sendo denominado leite de transição aquele produzido no período intermediário entre o colostro e o leite maduro ${ }^{1,11}$. Embora se considere como período transicional aquele compreendido entre o sexto e décimo dias pós-parto, poucos nutrientes atingem o décimo dia com seus valores definitivos; esta irregularidade na composição láctea dos primeiros dias pode ser atribuída a uma imaturidade fisiológica e metabólica da glândula mamária ${ }^{1}$. Assim, embora o processo de transição perdure por todo o primeiro mês de lactação, convencionou-se definir como leite maduro, aquele produzido posteriormente ao décimo quinto dia de vida ${ }^{1,11,15}$.

\section{Composição protéica}

O RN e o lactente são dotados de uma atividade anabólica intensa, dificilmente igualada em qualquer outro período de suas vidas; tal atividade necessita, pois, de uma oferta correspondente de nitrogênio a ser fornecida nos primeiros seis meses de vida ${ }^{2}$.

A necessidade protéica do RN de termo é estimada em cerca de 2,0 a 2,5 g/kg/dia, decrescendo gradualmente até chegar a $1,3 \mathrm{~g} / \mathrm{kg} /$ dia por volta do quarto mês ${ }^{16}$. O leite humano maduro fornece, em média, $1,2 \mathrm{~g}$ de proteína para cada $100 \mathrm{ml}$.

Deve-se levar em conta, no entanto, que o teor protéico do leite humano maduro foi, durante décadas, superestimado, por ter sido obtido a partir de seu conteúdo de nitrogênio total. Como a fração correspondente ao nitrogênio não protéico representa cerca de $25 \%$ do nitrogênio total no leite humano, desprende-se daí que sua concentração protéica real oscila ao redor de $0,9 \mathrm{~g} / \mathrm{d}^{1,12,17}$.

As proteínas do soro constituem, no leite humano, cerca de 60 a $90 \%$ de seu teor protéico total ${ }^{20}$. Sua composição inclui a alfa-lactalbumina, a lactoferrina, a lisozima, a soroalbumina, as imunoglobulinas e a betalactoglobulina. A alfa-lactalbumina, que constitui cerca de $40 \%$ das proteínas do soro do leite humano, é necessária para o transporte de ferro e ainda para a síntese de lactose na glândula mamária ${ }^{18}$.

A lactoferrina, a lisozima e as imunoglobulinas, especialmente a IgA secretória, são proteínas do soro do leite humano envolvidas no sistema de proteção. A lactoferrina, glicoproteína presente em concentrações elevadas no leite humano sob forma amplamente insaturada, possui a propriedade de ligar-se ao ferro, impedindo os microrganismos patogênicos de utilizar esse mineral para seu metabolismo. Efeito bacteriostático semelhante ao da lactoferrina também é exercido por outras proteínas presentes em menores proporções no leite humano, tais como aquelas que se ligam ao ácido fólico e à vitamina $\mathrm{B} 12^{14,19}$. A lisozima, enzima com ação lítica da parede celular bacteriana de microrganismos suscetíveis através da clivagem de peptídeoglicanos, é encontrada em maior quantidade no leite maduro $(0,014$ a $0,039 \mathrm{~g} / \mathrm{dl})$, ao contrário dos demais fatores da defesa, mais concentrados no colostro $^{19}$. Sua ação é sinérgica à da lactoferina e à da $\operatorname{Ig} \mathrm{A}$ secretória, possuindo efeito bactericida contra a maioria das bactérias Gram positivas e algumas Gram negativas. A IgA secretória representa cerca de $90 \%$ das imunoglobulinas presentes no colostro e leite maduro, sendo suas concentrações médias, nestas duas fases, respectivamente de $1,74 \mathrm{~g} / \mathrm{dl}$ e $0,1 \mathrm{~g} / \mathrm{dl}^{20}$. Trata-se de glicoproteína com estrutura molecular especial que lhe confere maior resistência às alterações de $\mathrm{pH}$ e a digestão por enzimas proteolíticas. É produzida, em sua maior parte, por células linfoplasmocitárias sensibilizadas, presentes na glândula mamária, oriundas dos tecidos linfóides 
associados a órgãos maternos como intestinos (GALT) e brônquios (BALT), que são integrantes dos sistemas imunes êntero e broncomamário ${ }^{12,14,16,21}$. A IgA secretória tem a propriedade de se ligar às membranas mucosas, impedindo a aderência dos microrganismos patogênicos. Age ainda através da aglutinação de microrganismos e da neutralização de enterotoxinas ${ }^{12,14,16}$.

A caseína, proteína láctea encontrada em concentrações variáveis nas diferentes espécies de mamíferos, é altamente resistente ao calor, sofrendo precipitação em $\mathrm{pH}$ igual ou inferior a cinco ou por ação enzimática ${ }^{5}$. Existem vários subtipos de caseína, predominando no leite humano, as frações beta-caseína (50\%) e kappa-caseína (20 a 27\% $)^{5}$.

Existe acentuada elevação do teor da caseína do leite humano durante a lactação, acompanhada de concomitante decréscimo dos níveis de proteínas do soro. Assim, a relação proteínas do soro/caseína, que é de 90:10 no início da lactação, modifica-se rapidamente no decorrer da mesma, atingindo valores de 60:40 ou até de 50:50 na fase do leite maduro 5 .

A caseína é constituída por um grupo de subunidades que tem a propriedade de formar micelas estáveis com cálcio e fósforo, conferindo a aparência branca do leite ${ }^{21}$. Tais micelas favorecem o transporte desses minerais em quantidades bem maiores do que seria possível apenas através de sua solubilidade. Assim, os conteúdos lácteos do cálcio e fósforo mostram correlação significativa com o teor de caseína ${ }^{16}$. As micelas do leite humano são pequenas, sendo seus coalhos, ou seja, os complexos insolúveis formados em decorrência da precipitação da caseína, mais tênues e frágeis. Tais características reduzem o tempo de esvaziamento gástrico, contribuindo para a maior digestibilidade do leite humano ${ }^{21}$.

O perfil de aminoácidos do leite humano é bastante adequado às características metabólicas do RN. O neonato, especialmente o prematuro, revela imaturidade de alguns sistemas enzimáticos, que se traduz por limitada capacidade para conversão de determinados aminoácidos.

A taurina, aminoácido condicionalmente essencial para o RN, em especial para o RN pré-termo, exerce importante papel na conjugação de sais biliares, aumentando a absorção lipídica, bem como no transporte de zinco; encontrada em concentrações elevadas em tecido cerebral, parece atuar como neuro-transmissor excitatório cerebelar, e ainda em tecido retiniano. A glutamina, também um aminoácido condicionalmente essencial, promove o crescimento de epitélio intestinal, sendo o principal combustível desse órgão durante período de estresse ${ }^{21}$. A carnitina, aminoácido também presente na fração solúvel do leite humano, parece não ser sintetizada por RN prétermo em quantidade suficiente para suas necessidades; daí a importância de sua inclusão na dieta de tais RN. A carnitina tem atuação marcante no metabolismo dos ácidos graxos de cadeia longa, facilitando seu transporte através da membrana mitocondrial, que permite a sua oxidação e parcial conversão a cetonas no fígado ${ }^{22}$.
Os aminoácidos taurina, glutamina e carnitina têm sido acrescentados às fórmulas lácteas destinadas a RN pré-termo, em concentrações semelhantes àquelas do leite humano, numa tentativa de reproduzir suas importantes funções.

\section{Funções das proteínas e pepitídeos do leite humano}

a) Nutritivas: proteínas do soro, caseína; fornecem peptídeos, aminoácidos e nitrogênio para o crescimento do lactente;

\section{b) Não nutritivas ${ }^{5,12,23}$;}

\section{b1) No trato gastrintestinal}

- fatores de crescimento: são hormônios polipeptidicos, tais como o fator de crescimento epidérmico (EGF), o fator de crescimento insulina simile 1 (IGF-1) e os fatores transformadores do crescimento alfa e beta. Eles promovem maturação da mucosa gastrintestinal, restringem a penetração de substâncias antigênicas potencialmente lesivas e demonstram ainda atividade antiinflamatória, suprimindo a função linfocitária;

- outros hormônios: citoquinas, prostaglandinas, somatostina e muitos outros; possuem funções tróficas, imunomoduladoras e antiinflamatórias;

- peptídeos: alguns são derivados da caseína e possuem atividades semelhantes ao ópio e à endorfina (peptídeos ou opióides e beta - casomorfinas), regulando a motilidade gastrintestinal. Outros como o peptídeo inibidor de gastrina, a bombesina, a colocistoquinina e a neurotensina, atuam sobre crescimento, maturação e regulação gastrintestinal.

\section{b2) Como enzimas}

O leite humano possui mais de sessenta enzimas, muitas das quais com papel fisiológico pouco conhecido. As enzimas lácteas podem ser divididas em três grupos, de acordo com o seu papel fisiológico:

- enzimas com atividade presente na glândula mamária ${ }^{24}$ : atuam no transporte e síntese de vários componentes do leite humano;

- enzimas com atividade predominante no recémnascido ${ }^{24}$ : atuam na digestão e/ou no metabolismo do RN, podendo ainda contribuir para a atividade antibacteriana do leite humano;

- enzimas lácteas sem função bem definida.

\section{b3) Como agentes antiinfecciosos}

- glicoproteínas e glicopeptídeos: as principais glicoproteínas presente no leite humano são a K-caseína, as imunoglobulinas $\operatorname{IgG}, \operatorname{IgM}, \operatorname{Ig}$ A e $\operatorname{Ig}$ A secretória, a lactoferrina, as moléculas de adesão celular solúveis ou seletinas, as mucinas e outras;

- fatores estimuladores da proliferação de colônias de leucócitos: granulócitos (G-CSF), macrófagos (M-CSF) ou ambos (GM-CSF); 
- fibronectina: substância que facilita a captação de vários tipos de partículas por células fagocitárias mononucleares.

\section{b4) Como agentes imunomoduladores}

As principais proteínas com função imunomoduladora são a prolactina, a IgA secretória antiidiotípica, a lactoferrina, a prostaglandina E2 e algumas citoquinas.

\section{b5) Como agentes antiinflamatórios}

O leite humano é pobre em fatores pró-inflamatórios mais é muito rico em agentes antiinflamatórios. As principais proteínas com atividade antiinflamatória são a lactoferrina, a lisozima, a IgA secretória, enzimas antioxidantes como a catalase e a glutation peroxidase, antiproteases como a alfa-1 antitripsina e a alfa-1 antiquimotripsinase e algumas citoquinas $^{5,12,23}$.

\section{Composição de carboidratos}

A lactose constitui cerca de $70 \%$ do conteúdo de carboidratos do leite humano; sua concentração no colostro oscila ao redor de $5,3 \mathrm{~g} / \mathrm{dl}$, elevando-se para $7 \mathrm{~g} / \mathrm{dl}$ no leite maduro ${ }^{16}$.

Ela fornece ao redor de 45 a $50 \%$ do conteúdo energético total do leite humano. Os outros carboidratos, presentes em concentrações muito inferiores são representados pela glicose $(14 \mathrm{mg} / \mathrm{dl})$, galactose (12 mg/dl), oligossacarídeos complexos (500 a 1200 mg/dl) e glicoproteínas ${ }^{5,16,25}$.

A lactose é um dissacarídeo e, como tal, necessita da presença de uma dissacaridase, a lactase, para ser hidrolisada em glicose e galactose. Existem evidências de que a alimentação precoce com leite humano estimula a atividade endógena da lactase em RN pré-termo ${ }^{26}$. Assim, a ingestão do leite humano pode facilitar a digestão da lactose.

As elevadas concentrações de lactose no leite humano são consideradas como de grande importância para o organismo do $\mathrm{RN}$ e do lactente, pois seu produto metabólico, a galactose, entra na constituição dos galactolipídeos integrantes do sistema nervoso central ${ }^{16}$. Ademais, o alto conteúdo daquele dissacarídeo acarreta grande acúmulo de água livre, ou seja, de água que não precisa ser obrigatoriamente excretada com sais pelos rins; esta constitui uma reserva para a termo-regulação, através da sudorese, nos lactentes amamentados ${ }^{25}$.

Lactentes e RN, inclusive os RN pré-termo, tem capacidade de absorver mais de $90 \%$ do conteúdo de lactose do leite humano ${ }^{26}$. A permanência de pequena quantidade de carboidrato na luz intestinal é considerada como um efeito fisiológico normal da alimentação com leite humano, resultando em algumas conseqüências benéficas para a criança, tais como ${ }^{26}$ :

- eliminação de fezes mais amolecidas, reduzindo a incidência de obstipação intestinal;
- promoção do crescimento da flora bacteriana não patogênica na luz intestinal em conjunto com o fator bífido levando à queda do $\mathrm{pH}$ e tornando o ambiente impróprio ao crescimento de bactérias patogênicas ${ }^{16}$;

- ação facilitadora sobre absorção de cálcio e fósforo na luz intestinal, o que poderia auxiliar na prevenção da doença metabólica óssea em RN pré-termo.

Durante vários anos os oligossacarídeos do leite humano foram valorizados apenas por seu papel como fator de crescimento para a flora de bifidobactérias na luz intestinal de crianças amamentadas. Atualmente, no entanto, existem fortes evidências de que os oligossacarídeos livres, bem como as glicoproteínas, seriam inibidores potentes da adesão bacteriana às superfícies epiteliais, etapa inicial dos processos infecciosos. Assim, tais compostos são considerados como receptores solúveis de antígenos bacterianos, com estrutura análoga à dos carboidratos de células epiteliais superficiais. Especula-se ainda a respeito de sua função como ligandinas para seletinas que promovem a interação entre leucócitos e endotélio, na fase inicial das reações inflamatórias ${ }^{5,27}$.

\section{Composição lipídica}

As gorduras constituem a maior fonte de energia do leite humano. Seu conteúdo no leite maduro varia entre 3 e $4 \mathrm{~g} / \mathrm{dl}$, aproximadamente 45 a $55 \%$ do valor calórico total; já o colostro possui concentração lipídica algo menor, em torno de 1,8 a $2,9 \mathrm{~g} / \mathrm{dl}$, que se eleva para valores intermediários $\left(2,9\right.$ a 3,6 g/dl) no leite de transição ${ }^{16}$.

As células mamárias alveolares sintetizam a gordura láctea, sendo tal síntese estimulada pelo esvaziamento da mama, especialmente através da amamentação, e ainda pela prolactina, secretada no lobo anterior da hipófise. A maior proporção da gordura láctea é formada a partir dos lipídeos circulantes, derivados da dieta e/ou dos depósitos maternos. Ademais, parte da gordura do leite humano pode ser sintetizada "de novo" na glândula mamária a partir da glicose, resultando na formação dos ácidos graxos saturados com 10 a 14 átomos de carbono ${ }^{12}$. A proporção desses ácidos graxos com cadeia média e intermediária aumenta quando a nutriz consome uma dieta pobre em gorduras e com elevado teor de carboidratos.

As células alveolares secretam os lípides para a luz do alvéolo sob a forma de glóbulos de gordura. Estes contem uma região central hidrofóbica, formada por triglicérides, ésteres colesteril e retinil, e uma membrana constituída por fosfolípides, proteínas, colesterol e enzimas. Alguns destes compostos são bipolares, estando localizados na interface óleo-água para possibilitar a estabilidade da emulsão de gordura no veículo lácteo aquoso $^{12}$.

Os triglicerídeos constituem cerca de $98 \%$ do teor de gorduras do leite humano, correspondendo o restante a pequenas quantidades de foslipídes $(0,7 \%)$, colesterol $(0,5 \%)$ e produtos da lipólise, tais como ácidos graxos livres, mono e diacilglicóis ${ }^{12}$. 
Os lípides do leite humano são facilmente digeríveis e absorvíveis em decorrência da ação combinada de vários fatores, tais como a organização do glóbulo de gordura, a composição de ácidos graxos e comprimento de suas cadeias, a distribuição dos ácidos graxos na molécula do triglicéride e as atividades enzimáticas complementares ${ }^{16,26}$. Existem duas lipases no leite humano, cujas quantidades são suficientes para hidrolisar 30 a $40 \%$ dos triglicérides em duas horas, complementando a ação das lipases gástrica e pancreática. A mais importante delas, a lipase estimulada por sais biliares, depende da presença de pequenas quantidades desses sais para participar da digestão intestinal dos lipídes lácteos, sendo ativa mesmo em RN prétermo $^{16,26}$. A outra é uma lipase lipoprotéica com ação na glândula mamária, facilitando a capitação e a hidrólise das lipoproteínas provenientes do plasma para o leite humano ${ }^{12}$.

Os principais ácidos graxos existentes no leite humano restringem-se aqueles com cadeias de 12 a 18 carbonos, ou seja, ácidos laúrico, mirístico, palmítico, palmitoléico, esteárico, oléico, linoléico e linolênico. Os ácidos linoléico e linolênico, considerados como ácidos graxos essenciais, são precursores dos ácidos graxos poliensaturados de cadeia longa (LCPUFA) - ácido araquidônico e ácido docosahexaenóico. Estes, sendo componentes dos fosfolípides das membranas celulares, exercem importante papel no crescimento e desenvolvimento do sistema nervoso, através da mielinização e também da função retiniana ${ }^{16,26,28}$. Ademais, são precursores dos mediadores inflamatórios, como prostaglandinas, prostaciclinas, tromboxanes e leucotrienos ${ }^{28}$.

O RN pré-termo, em especial aquele de muito baixo peso, possui capacidade limitada para sintetizar os LCPUFA a partir de seus precursores, de onde se infere a importância de sua oferta a partir do leite humano ${ }^{28}$.

Dentre os esteróis detectados no leite humano, o colesterol representa $90,1 \%$ e suas concentrações lácteas, maiores no colostro, oscilam em torno de 10 a $20 \mathrm{mg} / \mathrm{dl}^{12,29}$. Ao nascer, os RN alimentados com leite humano recebem cerca de $50 \%$ das necessidades de colesterol por essa via devendo os restantes $50 \%$ ser sintetizados pelo organismo (fígado e tecido gorduroso). Os lactentes consomem quantidades relativamente grandes de colesterol através do leite humano (25 mg/kg/dia) quando comparados com os adultos $(4,3 \mathrm{mg} / \mathrm{kg} / \mathrm{dia})^{12,29}$. Os maiores níveis séricos de colesterol durante a fase de lactação parecem ser importantes para induzir a maturação dos sistemas enzimáticos que metabolizam tal lipídeo, podendo influenciar a capacidade futura de regulação de suas concentrações plasmáticas e auxiliar na prevenção da doença aterosclerótica ${ }^{29}$. O colesterol é necessário ainda para a mielinização do sistema nervoso, para a produção de hormônios esteróides, de ácidos biliares e também da vitamina $\mathrm{D}$.

Quanto aos fosfolípides do leite humano, suas concentrações, na fase do leite maduro, variam em torno de $25 \mathrm{mg} / \mathrm{dl}$, sendo mais elevadas no colostro ${ }^{12}$. As principais classes de fosfolípides lácteos são representadas por esfingomielina (30-37\%) fosfatidilcolina (26\%), fosfatidiletanolamina (27\%), fosfatidilserina ( $8 \%$ ) e fosfatidilinositol $(6 \%)^{12}$.

A composição nutricional do leite humano, especialmente em relação ao componente lipídico, apresenta variações biológicas inerentes ao processo da lactação $0^{30,31,32}$. Durante a mamada existe uma elevação significativa do conteúdo de gorduras, possuindo o leite final ou posterior por volta de três vezes a concentração lipídica do leite inicial ou anterior. Não foram detectadas alterações nos valores de ácidos graxos entre o início e o fim da mamada. Estas diferenças entre os leites inicial e final poderiam ser decorrentes do fenômeno mecânico de absorção dos glóbulos de gordura à superfície secretora e aos dutos dos alvéolos mamários, resultando em sua liberação tardia durante a mamada ${ }^{30}$.

Foi demonstrado que a síntese lipídica na glândula mamária está sob o controle da prolactina, hormônio cuja secreção é estimulada pela sucção do $\mathrm{RN}^{31}$. Existe considerável elevação de seus níveis sanguíneos entre o início e o fim da mamada, o que poderia estar relacionado com a maior quantidade de gordura presente no leite posterior. Sabe-se ainda que sua secreção obedece a um ritmo circadiano, talvez o fator responsável pelas variações do conteúdo lipídico no decorrer do dia. As flutuações na composição de gorduras do leite humano poderiam ainda ter um significado fisiológico, permitido ao RN desenvolver mecanismo de percepção de diferentes sabores, bem como de controle do apetite e da sede ${ }^{31}$.

\section{Composição de micronutrientes}

O conteúdo mineral no colostro é superior ao do leite maduro. Estes níveis parecem ser, na maioria das vezes, suficientes para a nutrição do RN e não resultam em sinais ou sintomas de intolerância.

Os macrominerais do leite humano incluem sódio, potássio, cloreto, cálcio, magnésio, fósforo e sulfato. $\mathrm{O}$ fator responsável pelas maiores variações nos níveis lácteos desses macrominerias é o tempo de lactação: enquanto os conteúdos de sódio e cloreto diminuem com o passar dos meses, aqueles de potássio, cálcio, fósforo e magnésio se elevam ${ }^{12}$.

\section{Sódio}

Sua concentração no leite humano maduro, cujo valor corresponde a um terço daquele existente na fase de colostro, oscila ao redor de $7 \mathrm{mEq} / \mathrm{l}$; estes níveis são geralmente suficientes para preencher as necessidades dos RN de termo.

Os RN pré-termo, especialmente os de muito baixo peso, não possuem mecanismos bem desenvolvidos para conservação de sódio, sendo sua fração de excreção elevada nos primeiros dez a catorze dias após o nascimento. 
Assim, o conteúdo do mineral existente no leite humano pode resultar numa entidade conhecida como "hiponatremia verdadeira do RN pré-termo extremo". O leite produzido por mães de RN pré-termo contém maiores concentrações de sódio durante o primeiro mês de lactação, mas mesmo estas são insuficientes para as elevadas necessidades desses RN, sendo necessária a suplementação ${ }^{26,33}$.

Níveis elevados de sódio e cloreto podem ser observados no leite de nutrizes com mastite, com valores maiores daquele proveniente da mama mais afetada. Concentrações mais altas desses minerais são também características das fases de pré-colostro, colostro inicial e involução da lactação. Em todas estas situações, as vias paracelulares existentes entre as células mamárias alveolares estão permeáveis, possibilitando a entrada de componentes do fluído extracelular nos espaços alveolares $^{32}$.

\section{Potássio}

Seus níveis no colostro são um pouco maiores em relação aos observados no leite maduro, sendo estes últimos da ordem $14 \mathrm{mEq} / \mathrm{l}$. Tal concentração se eleva no decorrer da lactação, sendo seus valores, em qualquer fase, adequados as necessidades dos RN de termo e pré-termo ${ }^{12}$.

\section{Cálcio e fósforo}

Tanto o colostro como o leite maduro contém aproximadamente 28 a $33 \mathrm{mg} / \mathrm{dl}$ de cálcio e 13 a $15 \mathrm{mg} / \mathrm{dl}$ de fósforo. Estas quantidades são suficientes para que o $\mathrm{RN}$ de termo em aleitamento materno exclusivo apresente crescimento adequado, sem sinais de deficiência ou alterações esqueléticas ${ }^{4,12,33}$.

O cálcio, bem como o magnésio, estão ligados ao fosfato nas micelas de caseína, o que contribui para o transporte dos minerais em quantidade maior do que seria possível através de sua solubilidade. O cálcio também se encontra no leite humano sob a forma ionizado, constituindo vários compostos como citrato e fosfato ${ }^{12,16,31}$. Assim, a concentração láctea deste mineral provavelmente varia em função dos conteúdos de citrato e caseína; sabese que os níveis de cálcio, magnésio e fósforo elevam-se no leite humano de acordo com o tempo de lactação, acompanhando a ascensão do teor de caseína ${ }^{12}$.

$\mathrm{O}$ leite produzido por mães de $\mathrm{RN}$ pré-termo contém as mesmas quantidades de cálcio e fósforo em relação ao produzido por mães de $\mathrm{RN}$ de termo ${ }^{26,34}$. Considerando-se uma ingestão láctea média de 150 a $200 \mathrm{ml} / \mathrm{kg} / \mathrm{dia}$, obteremos uma oferta aproximada de 45-60 mg/kg/dia de cálcio e 22-30 mg/kg/dia de fósforo; esses valores são insuficientes para satisfazer as necessidades nutricionais de $\mathrm{RN}$ pré-termo, especialmente daqueles de muito baixo peso, que devem ser comparáveis à incorporação intra-uterina do terceiro trimestre da gestação (130 a 150 mg/kg/dia de cálcio e 75 a 85 mg/kg/dia de fósforo $)^{34,35}$. Assim, a ingestão de leite humano não suplementado predispõe à chamada "doença metabólica óssea" nesses RN.

\section{Magnésio}

Suas concentrações em colostro e leite maduro são semelhantes oscilando ao redor de 2,5 a 3,3 mEq/l. Não se observa hipomagnesemia em RN de termo em aleitamento materno exclusivo. Nos RN de muito baixo peso, porém, alguns autores detectaram retenção inadequada de magnésio quando os mesmos foram alimentados com leite humano da própria mãe não suplementado ${ }^{35}$. Segundo tais autores, os pequenos prematuros nascem com reservas especialmente baixas desse íon, uma vez que seu depósito intra-uterino é formado no terceiro trimestre da gestação. Não existe, no entanto, unanimidade entre os pesquisadores a respeito da necessidade de suplementação de magnésio para RN de muito baixo peso alimentados com leite humano ${ }^{26}$.

\section{Microminerais, elementos - traço ou oligoelementos}

São substâncias que entram na composição de porção inferior a $0,01 \%$ da massa corpórea ${ }^{12}$. São elas: zinco, cobre, ferro, manganês, selênio, iodeto, fluoreto, molibdênio, cobalto, crômio, níquel e cádmio.

As concentrações de zinco no leite humano demonstram queda progressiva no decorrer da lactação, com valores aproximados de 500 a $900 \mathrm{mcg} / \mathrm{dl}$ nos três primeiros dias de colostro que caem para cerca de 250 a $400 \mathrm{mcg} / \mathrm{dl}$ no início da fase de leite maduro e para 80 a $100 \mathrm{mcg} / \mathrm{dl}$ após quatro a sete meses. A vasta maioria dos RN de termo em aleitamento materno exclusivo não manifesta deficiência nesse mineral. Isso se deve à sua elevada biodisponibilidade no leite humano ${ }^{36}$.

Foram descritos, porém, alguns casos de deficiência transitória e sintomática de zinco em $\mathrm{RN}$ em aleitamento materno exclusivo ${ }^{36}$. As concentrações deste elemento no leite de suas mães revelaram-se anormalmente baixas, não sendo corrigidas pela suplementação materna com sulfato de zinco. Estes dados sugerem a presença de uma falha no processo de transferência do zinco do sangue para o leite humano.

O RN de muito baixo peso em aleitamento materno é predisposto à deficiência de zinco, provavelmente em decorrência das reservas insuficientes, da queda progressiva dos níveis lácteos no decorrer da lactação, das excessivas perdas fecais e das maiores necessidades para o crescimento $^{16}$. Segundo alguns autores, os níveis de 
zinco recomendados na dieta $(500 \mathrm{mcg} / \mathrm{kg} / \mathrm{dia})$ para se atingir a incorporação semelhante à intra-uterina só são conseguidos através da suplementação do leite humano, porém, não existe unanimidade entre os pesquisadores a respeito da necessidade de tal rotina ${ }^{26}$.

Em relação aos níveis de cobre do leite humano, seus valores são um pouco superiores no colostro em relação ao início da fase de leite maduro, mantendo-se, a partir daí, relativamente constantes. Tais valores são suficientes para preencher as necessidades de RN de termo em aleitamento materno exclusivo. Quanto aos RN de muito baixo peso, a oferta recomendada é de aproximadamente $100 \mathrm{mcg} / \mathrm{kg} / \mathrm{dia}$, que nem sempre pode ser fornecida pelo leite humano não suplementado. Esses RN nascem com reservas hepáticas de cobre diminuídas e apresentam, com freqüiência, perdas fecais excessivas; disto resulta uma maior susceptibilidade à deficiência do mineral durante a fase do crescimento rápido ${ }^{37}$. Não existe, no entanto, unanimidade entre os autores a respeito da necessidade de suplementação de cobre para RN de muito baixo peso em aleitamento materno exclusivo ${ }^{26}$.

Quanto às concentrações de ferro existentes no leite humano, mais elevadas no início da lactação, elas parecem ser suficientes para RN de termo, pois raramente se observa anemia ferropriva nesses RN quando em aleitamento materno exclusivo. Este fato pode ser explicado pela elevada biodisponibilidade de ferro do leite humano, pois, sabe-se que seu conteúdo, em valor absoluto, é baixo. A maior biodisponibilidade do ferro do leite humano pode resultar de seu menor conteúdo de proteínas e fósforo, bem como dos maiores níveis de lactose e vitamina $\mathrm{C}^{38}$. O baixo teor de ferro no leite humano é desejável para permitir que a lactoferina permaneça, em sua maior parte, sob forma insaturada, mantendo suas propriedades bacteriostáticas ${ }^{5,38}$.

Quanto aos RN pré-termo, especialmente aqueles de muito baixo peso, sabe-se que seus depósitos de ferro ao nascimento são baixos; ademais, as várias colheitas sanguíneas a que são submetidos contribuem para a depleção. Desta forma, tais RN, ao atingirem a idade pósconceptual correspondente ao termo, deverão necessitar de suplementação de ferro para evitar a anemia ferropriva no final do primeiro ano de vida, tendo em vista a baixa concentração láctea do mineral ${ }^{4,38}$.

A concentração de flúor no leite humano é baixa, mesmo em áreas contendo água fluorada $(0,4$ a $1,5 \mathrm{mcg} / \mathrm{dl}$ no leite maduro) ${ }^{12}$. Sabe-se ainda que lactentes em aleitamento materno exclusivo não ingerem água. Alguns autores recomendam, pois, suplementação com $0,25 \mathrm{mg} /$ dia para tais crianças nos primeiros seis meses, enquanto outros preferem iniciá-la após o sexto mês e apenas em locais onde a água não é fluorada ${ }^{39}$.

Quanto aos níveis de iodeto no leite humano, sua variação é pequena entre as fases de lactação, correspondendo a $12 \mathrm{mcg} / \mathrm{dl}$ no colostro e a aproximadamente 7 a $14 \mathrm{mcg} / \mathrm{dl}$ no leite maduro. Sua concentração láctea, no entanto, oscila bastante de acordo com a dieta materna e com a região geográfica.

As concentrações lácteas de manganês oscilam entre 0,2 e $0,6 \mathrm{mcg} / \mathrm{dl}$, tanto em colostro como no início da fase de leite maduro e seus níveis tendem a cair no decorrer da lactação ${ }^{12}$.

O selênio é um alimento-traço essencial para a atividade da enzima glutationa peroxidase, com ação antioxidante complementar à da vitamina E. Sua concentração no leite humano é elevada no início da lactação (4 mcg/dl), em associação à fração protéica; os níveis lácteos decaem com o passar dos meses, sendo variáveis de acordo com a região geográfica e com a dieta materna $(0,7 \text { a } 3,3 \mathrm{mcg} / \mathrm{dl})^{40}$. Existe uma forte correlação entre o conteúdo lácteo de selênio, a atividade da enzima glutationa peroxidase no leite humano e os níveis sangüíneos do mineral no lactente ${ }^{40}$.

Em relação aos demais oligoelementos, seus níveis lácteos costumam ser suficientes para a nutrição dos $\mathrm{RN}$ de termo ou pré-termo. Em leite maduro, as concentrações de molibolênio oscilam entre 0,1 e $0,2 \mathrm{mcg} / \mathrm{dl}$, as de cobalto entre 0,01 e $0,02 \mathrm{mcg} / \mathrm{dl}$, as de crômio entre 0,02 e $0,04 \mathrm{mcg} / \mathrm{dl}$ e as de níquel entre 0,05 e $0,2 \mathrm{mcg} / \mathrm{dl}$. A nutriz que fuma cerca de 20 cigarros por dia possui nível lácteo de cádmio equivalente ao dobro daquele observado em nutrizes não fumantes. $\mathrm{O}$ leite humano possui ainda pequenas quantidades de radioisótopos, que resultam de vários eventos atômicos ${ }^{12}$.

\section{Composição vitamínica}

O conteúdo vitamínico do leite humano é afetado por vários fatores, dos quais o mais importante é o estado nutricional materno. Em geral, quando a oferta materna de vitaminas é baixa, seus níveis lácteos são também baixos e respondem à suplementação; quando, no entanto, a oferta materna é elevada, as concentrações lácteas aproximamse de um valor máximo constante, sendo menos responsivas à suplementação ${ }^{40}$.

Os RN de termo, de mães eutróficas e com dieta adequada, parecem possuir, ao nascimento, reservas suficientes de vitaminas, com possível exceção da vitamina K. O leite humano pode preencher suas necessidades, desde que sejam ingeridos 750 a $1000 \mathrm{ml}$ por dia.

\section{Vitaminas hidrossolúveis}

A maioria das vitaminas hidrossolúveis tem concentrações baixas no colostro, que aumentam no decorrer da lactação ${ }^{16}$. A vitamina B2 (riboflavina) pode fugir a essa regra, pois seu nível lácteo, bastante influenciado pela dieta materna, costuma ser elevado no início da lactação e decair durante os meses seguintes. 
A suplementação vitamínica materna, conforme citado anteriormente, só aumenta a concentração láctea em mães com oferta suficiente de tais substâncias; constituem exceções as vitaminas B12 e niacina cujo incremento no ingestão materna pode elevar os níveis lácteos materno em mães com concentrações orgânicas adequadas ${ }^{12,40}$. Podem ser detectados sinais clínicos de deficiência de vitamina B12 nos lactentes em aleitamento materno exclusivo cujas mães sejam vegetarianas estritas; tal deficiência resulta, muitas vezes, em lesão neurológica grave e permanente $\mathrm{e}^{12,40}$. Assim, deve-se indicar suplemento de vitamina B12 para tais nutrizes.

As concentrações lácteas de vitamina B6 (piridoxina) podem estar drasticamente reduzidas em mães com história de utilização prolongada de contraceptivos orais $^{40}$.

\section{Vitaminas lipossolúveis}

Suas concentrações são geralmente mais elevadas no colostro, sofrendo queda progressiva com o transcorrer da lactação ${ }^{12,40}$.

Enquanto os níveis lácteos das vitaminas hidrossolúveis são largamente influenciadas pela dieta materna recente, os teores das vitaminas lipossolúveis parecem refletir em especial os depósitos vitamínicos maternos, resultantes dos padrões dietéticos anterior e habitual $^{1,40,41}$.

O termo vitamina A compreende uma família de compostos vitamínicos, muitos dos quais estão presentes no leite humano, tais como ésteres retinil, retinol e betacaroteno. O conteúdo lácteo de retinol livre é muito baixo, pois mais de $95 \%$ da vitamina A do leite humano está presente sob forma de ésteres retinil ${ }^{12,40}$.

O leite produzido por nutrizes eutróficas contém concentração adequada de vitamina $\mathrm{A}$, enquanto aquele produzido por mulheres desnutridas fornece quantidade insuficiente da substância para o lactente. O conteúdo lácteo é pouco influenciado por oferta diária inferior a $15 \mathrm{mg}$, mas a ingestão superior a $15 \mathrm{mg}$ por dia resulta em acentuada elevação de seu valor ${ }^{12,40}$. Vários autores recomendam suplementação da vitamina A para RN prétermo devido a seus baixos depósitos ao nascimento, a suas elevadas velocidades de crescimento e ainda à reduzida absorção gastrintestinal das vitaminas lipossolúveis ${ }^{12,35}$.

A vitamina $\mathrm{E}$ inclui um grupo de compostos com vários graus de atividade biológica, dos quais o mais ativo é o alfa tocoferol. Age primariamente como antioxidante, promovendo a remoção dos radicais livres e protegendo as membranas celulares contra a peroxidação dos LCPUFA $^{12}$. Sua deficiência, especialmente em RN prétermo, pode resultar em anemia hemolítica, sendo seu nível sérico parcialmente relacionado às concentrações de LCPUFA, ferro e selênio ${ }^{12,40}$.
O leite humano maduro contém níveis adequados de vitamina $\mathrm{E}$ para o $\mathrm{RN}$ de termo, mas tais concentrações podem ser insuficientes para os RN pré-termo. Existe grande variação individual de seu conteúdo lácteo; ademais, os níveis no leite humano dependem do estágio da lactação, sendo mais elevados no colostro e decaindo durante semanas seguintes, No leite produzido por mães de RN pré-termo, a concentração de vitamina E é estável durante todo o primeiro mês de lactação ${ }^{12,35,42}$.

As vitaminas D2 (ergocalciferol) e D3 (colecalciferol) são convertidas a seus metabólicos ativos, 25-OH colecalciferol e 1,25-(OH) calecalciferol, respectivamente, no fígado e nos rins. ${ }^{2}$ Tais compostos tem papel fundamental no metabolismo de cálcio e fósforo e no processo de mineralização óssea. A vitamina $\mathrm{D}$ pode ainda ser sintetizada endogenamente, na epiderme, por ação da luz solar.

A concentração de vitamina D no leite humano é baixa; assim, RN e lactentes em aleitamento materno exclusivo não recebem quantidade suficiente para promover e assegurar mineralização óssea adequada.

Tendo em vista a dificuldade de se quantificar a reposição a luz solar, recomenda-se suplementação de todos os RN e lactentes, de termo ou pré-termo, com 400 a 800 UI por dia de vitamina $\mathrm{D}^{12,35,40,42}$.

Existem diferentes compostos naturais com atividade da vitamina $\mathrm{K}$ : a vitamina $\mathrm{K} 1$ (filoquinona) é a forma predominante na dieta, enquanto a vitamina $\mathrm{K} 2$ (menaquinona) é sintetizada por bactérias presentes na luz intestinal. Sua função principal é a síntese de proteínas relacionadas ao fenômeno da coagulação sanguínea ${ }^{12}$.

A vitamina $\mathrm{K}$ esta presente em concentrações semelhantes ao colostro e no leite maduro, permanecendo estável durante os seis primeiros meses de lactação ${ }^{12}$.

Lactentes em aleitamento materno exclusivo não atingem níveis adequados de vitamina $\mathrm{K}$ em seu organismo, estando mais propensos à doença hemorrágica. Os níveis lácteos de vitamina $\mathrm{K}$ são insuficientes para impedir o desenvolvimento de deficiência após dois meses de lactação, mesmo em crianças que recebam tal vitamina por via intramuscular ao nascimento. Assim, tem-se recomendado repetição da dose em RN de termo para prevenção da doença hemorrágica ${ }^{12,40,43}$.

\section{CONSIDERAÇÕESFINAIS}

Esta detalhada explanação a respeito da composição do leite humano mostra que este alimento é o ideal para se nutrir adequadamente os recém-nascidos e os lactentes. $\mathrm{O}$ seu perfil protéico, lipídico e de carboidratos preenche plenamente todas as necessidades das crianças, principalmente nos seus primeiros meses de vida, promovendo um crescimento saudável.

Além disso, vale ressaltar as imúneras vantagens do leite humano em relação às suas propriedades 
imunológicas, antiinfecciosas e o seu papel na prevenção de afecções futuras, como as doenças cárdio-vasculares.

Em relação ao RN pré-termo, apesar de existirem inadequações em relação ao teor protéico, de cálcio, fósforo e sódio, principalmente, o leite humano, pelos aspectos já comentados, ainda é o melhor alimento.

Calil VMLT, Falcão MC. Human milk composition: the ideal nutrition for infants. Rev Med (São Paulo) 2003 jan.-dez.;82(1-4):1-10.

\begin{abstract}
All women should be encourages to breast-fed their infants. Despite the advent of cowmilk formula, no artificial formula is equal to breast milk. The breast-feeding has many advantages: correct temperature and requires no sterilization, prevention of infections and the psychological benefits to mothers and children are obvious. The human milk composition is adequate in proteins, carbohydrates and fats in order to improve the best development. Thus, breast-feeding is recommended for the first two years of life.
\end{abstract}

KEYWORDS: Milk, human/chemistry. Milk, human/metabolism. Infant nutrition. Breast feeding.

\title{
REFERÊNCIAS
}

1. Anderson GH. Human milk feeding. Pediatr Clin North Am 1985;32:335-53.

2. Breastfeeding and the use of human milk. American Academy of Pediatrics. Work Group of Breastfeeding. Pediatrics 1997;100:1035-43.

3. Nutrition Committee of the Canadian Pediatric Society. Committee on Nutrition of the American Academy of Pediatrics. Breast-feeding. Pediatrics 1978;62:591-5.

4. Bates CJ, Prentice A. Breast milk as a source of vitamins, essential minerals and trace elements. Pharmacol Ther 1994;62:193-8.

5. Kunz C, Rodriguez-Palmero M, Koletzko B, Jensen R. Nutritional and biochemical properties of human milk, part I: general aspects, proteins and carbohydrates. Clin Perinatol 1999;26:307-33.

6. Koldovsky O. Hormones in milk. Vitam Horm 1995;50:7786.

7. Lucas A, Morley R, Cole TJ, Lister G, Leeson-Payne, C. Breast milk and subsequent intelligence quotient in children born preterm. Lancet 1992;339:261-4.

8. Koletzko S, Sherman P, Corey M, Griffiths A, Smith C. Role of infant feeding practices in development of Crohn's disease in childhood. Br Med J 1989;298:1617-20.

9. Saarinen VM, Kajosaari M. Breast feeding as prophylaxis against atopic disease: prospective follow-up until 17 years old. Lancet 1995;346:1065-71.

10. Wilson AC, Forsyth JS, Greene SA, Irvine L, Hau C, Howie PW. Relation of infant diet to childhood health: seven year follow-up of cohort of children in Dundee infant feeding study. Br Med J 1998;316:21-5.

11. Macy IG. Composition of human colostrum and milk. Am J Dis Child 1949; 78: 589-603.

12. Rodriguez-Palmero M, Koletzko B, Kunz C, Jensen R. Nutritional and biochemical properties of human milk: II. Lipids, micronutrients and bioactive factors. Clin Perinatol 1999;26(2):335-59.

13. Peitersen B, Bohn L, Andersen H. Quantitative determination of immunoglobulins, lysozyme and certain electrolytes in breast milk during the entire period of lactation, during a 24 hours period and in milk from the individual mammary gland. Acta Pediatr Scand 1975;64:709-17.

14. Calil VMLT, Leone CR, Ramos JLA. Composição nutricional do colostro de mães de recém-nascidos de termo adequados e pequenos para a idade gestacional. I - Principais vantagens do leite humano. Pediatria (São Paulo) 1992;14(1):9-13.

15. Ministério da Saúde. Recomendações técnicas para o funcionamento de bancos de leite humano. 3a ed. Brasília: Secretaria de Políticas de Saúde; 1998. p.1-48.

16. Calil VMLT, Leone CR, Ramos JLA. Composição nutricional do colostro de mães de recém-nascidos de termo adequados e pequenos para a idade gestacional. II - Composição nutricional do leite humano nos diversos estágios da lactação. Vantagens em relação ao leite de vaca. Pediatria (São Paulo) 1992;14(1):14-23.

17. Räihä N. Milk protein quantity and quality in term infants: intakes and metabolic effects during the first six months. Acta Paediatr Scand 1989;351(suppl):24-8.

18. Tikanoja T, Simell O, Vükari M, Järvenpää AL. Plasma amino acids in term neonates after a feed of human milk or formula. II - Characteristic changes in individual amino acids. Acta Paediatr Scand 1982;71(3):391-7.

19. Jakobson I, Lindberg T, Benediktsson B, Hansson BG. Dietary bovine beta - lactoglobulin is transfered to human milk. Acta Paediatr Scand 1985;74:342-5.

20. Goldman AS, Smith CW. Host resistance factors in human milk. J Pediatr 1973;82(6):1082-90.

21. Ogra SS, Ogra PL. Immunologic aspects of human colostrum and milk. I-Distribution, characteristics and concentrations of immunoglobulins at different times after the onset of lactation. J Pediatr 1978;92:546-9.

22. Schanler RJ. Human milk for preterm infants: nutritional and immune factors. Semin Perinatol 1989;13:69-77.

23. Borum PR. Carnitine in neonatal nutrition. J Child Neurol 1995;10(suppl 2):525-31.

24. Garofalo RP, Goldman AS. Expression of functional immunomodulatory and anti-inflammatory factors in human milk. Clin Perinatol 1999;26(2):361-77.

25. Patil KP, Rangnekar NR. Lactate dehydrogenase and its 
isoenzymes in human milk - a preliminary study. Clin Chem 1983;29:1568-70.

27. Schanler RJ, Hurst NM, Lau C. The use of human milk and breastfeeding in premature infants. Clin Perinatol 1999;26(2):379-98.

28. Genzel BO, Wahle J, Koletzko B. Fatty acid composition of human milk during the $1^{\text {st }}$ month after term and preterm delivery. Eur J Pediatr 1997;156:142-8.

29. Demmelmair H, Baumhever M, Koletzko B, Dokoupil K, Kratl G. Metabolism of U13C-labeled linoleic acid in lactating woman. J Lipid Res 1998;39:1389-94.

30. Decsi T, Fekete M, Koletzko B. Plasma lipid and apolipoprotein concentrations in full term infants fed formula supplemented with long- chain polyunsaturated fatty acids and cholesterol. Eur J Pediatr 1997;156:397-403.

31. Hytten FE. Clinical and chemical studies in human lactation. Br Med J 1954;2(1):175-82.

32. Hall B. Uniformity of human milk. Am J Clin Nutr 1979;32:304-12.

33. Becker M, Fiori RM. Fatores maternos associados ao lactócrito de leite humano. Pediatria (São Paulo) 1983;5:371-5.

34. Calil VMLT, Leone CR, Ramos, JLA. Composição nutricional do colostro de mães de recém-nascidos de termo adequados e pequenos para a idade gestacional III. Condições que alteram a composição nutricional do leite humano. Pediatria (São Paulo) 1992;14(1):24-9.

35. Atkinson SA. Calcium, phosphorus and vitamin D needs of low birthweight infants on various feedings. Acta Paediatr Scand 1989;351(suppl.):104-8.???

37. Atkinson SA, Radde IC, Anderson GH. Macromineral balances in premature infants fed their own mothers milk or formula. J Pediatr 1983;102(1):99-106.

38. Ziegler EE. Infants of low- birth-weight: special needs and problems. Am J Clin Nutr 1985;41:440-6.

39. Fransson GB, Lönnerdal B. Iron, copper, zinc, calcium and magnesium in human milk fat. Am J Clin Nutr 1984;39:1859.

40. Pereira GR, Barbosa NMM. Controversies in neonatal nutrition. Pediatr Clin North Am 1986:33(1):65-89.

41. Picciano MF. Human milk: nutritional aspects of a dynamic food. Biol Neonate 1998;74:84-93.

42. Jelliffe DB, Jelliffe EFP. The volume and composition of human milk in poorly nourished communities. A review. Am J Clin Nutr 1978;31(3):492-515.

43. Greer FR, Marshall SF, Foley AL, Suttie JW. Improving the vitamin $\mathrm{K}$ status of breastfeeding infants with maternal vitamin K supplements. Pediatrics 1997;99:88-103. 